\title{
TOLERÂNCIA DIFERENCIAL DE VARIEDADES DE CANA-DE-AÇÚCAR A ESTRESSE POR HERBICIDAS $\left({ }^{1}\right)$
}

\author{
RENATO RODRIGUES FERREIRA $\left({ }^{*}\right)$; FABRÍCIO TADEU RODRIGUES DE OLIVEIRA $\left({ }^{2}\right)$; \\ FABRÍCIO DE SOUZA DELITE $\left({ }^{3}\right)$; RICARDO ANTUNES AZEVEDO $\left({ }^{3,5}\right)$; MARCELO NICOLAI $\left({ }^{4}\right)$; \\ SAUL JORGE PINTO DE CARVALHO $\left({ }^{4}\right)$; PEDRO JACOB CHRISTOFFOLETI $\left({ }^{4,5}\right)$; \\ ANTONIO VARGAS DE OLIVEIRA FIGUEIRA $(2,5)$
}

\begin{abstract}
RESUMO
Este trabalho foi desenvolvido com o objetivo de realizar triagem primária para caracterização da tolerância de variedades SP e CTC de cana-de-açúcar à aplicação de dez herbicidas comumente recomendados para manejo de plantas daninhas nesta cultura. Dois experimentos foram desenvolvidos com esquema fatorial entre variedades de cana-de-açúcar e onze tratamentos herbicidas. No primeiro experimento utilizaram-se sete variedades SP (fatorial 7 x 11): SP80-1842, SP80-3280, SP83-2847, SP87-344, SP87-396, SP89-1115 e SP90-3414. No segundo experimento, foram avaliadas seis variedades CTC (fatorial 6 x 11): CTC1, CTC2, CTC3, CTC4, CTC5 e CTC6. Os tratamentos herbicidas aplicados em pós-emergência inicial foram: ametryn, ametryn + trifloxysulfuron-sodium, clomazone, diuron + hexazinone, isoxaflutole, imazapic, 2,4-D, tebuthiuron, sulfentrazone, MSMA e testemunha sem aplicação. Avaliou-se massa fresca, altura, teor de clorofila (índice SPAD) e perfilhamento, todos em termos percentuais relativos à testemunha sem aplicação. Constatou-se tolerância diferencial das variedades de cana-de-açúcar aos herbicidas comumente utilizados na cultura. As variedades SP80-3280 e CTC2 foram as mais tolerantes aos tratamentos herbicidas, podendo ter esta característica explorada em programas de melhoramento genético.
\end{abstract}

Palavras-chave: índice SPAD, herbicidas, fitotoxicidade, Saccharum.

\section{ABSTRACT \\ DIFFERENTIAL TOLERANCE OF SUGARCANE VARIETIES TO HERBICIDE STRESS}

This work was carried out with the objective of screening for tolerance response of SP and CTC sugarcane varieties to application of ten herbicides commonly recommended to weed management in this crop. Two trials were evaluated with factorial design between the sugarcane varieties and eleven herbicide treatments. In the first experiment, seven SP varieties were used (factorial 7 x 11): SP80-1842, SP80-3280, SP83-2847, SP87-344, SP87-396, SP89-1115 and SP90-3414. In the second experiment, six CTC varieties were evaluated (factorial $6 \times 11$ ): CTC1, CTC2, CTC3, CTC4, CTC5 and CTC6. The post-emergence-applied herbicide treatments were: ametryn, ametryn + trifloxysulfuron-sodium, clomazone, diuron + hexazinone, isoxaflutole, imazapic, 2,4-D, tebuthiuron, sulfentrazone, MSMA and check without application. The variables evaluated were: fresh mass, height, SPAD index and tillering: Valves here considered as relative percentage to the untreated control. Differential tolerance of sugarcane varieties was observed regarding to application of the tested herbicides. SP80-3280 and CTC2 were the most tolerant varieties to herbicide application, and might have this characteristic exploited by sugarcane breeding programs.

Key words: SPAD index, herbicides, phytotoxicity, Saccharum.

$\left({ }^{1}\right)$ Recebido para publicação em 27 de agosto de 2008 e aceito em 30 de março de 2010.

(2) Laboratório de Melhoramento de Plantas, CENA/USP. Caixa Postal 96, CEP 13400-970 Piracicaba (SP), Brasil. E-mail: rrferrei@cena.usp.br ( $\left.{ }^{*}\right)$ Autor correspondente.

$\left({ }^{3}\right)$ Departamento de Genética, ESALQ/USP, Piracicaba (SP), Brasil. E-mail: raazeved@esalq.usp.br

$\left({ }^{4}\right)$ Departamento de Produção Vegetal, ESALQ/USP, Piracicaba (SP), Brasil. E-mail:pjchrist@esalq.usp.br

$\left({ }^{5}\right)$ Bolsistas do CNPq. 
A cana-de-açúcar, mesmo sendo eficiente na utilização dos recursos disponíveis para seu desenvolvimento e apesar de possuir mecanismo fotossintético do tipo C4, é muito afetada pela competição com as plantas daninhas, pois, nos estádios iniciais de desenvolvimento, a brotação e o crescimento são lentos (ProcópIo et al., 2004a). Por exemplo, infestações de Cyperus rotundus reduzem em até $45 \%$ a produtividade da cana-soca com 125 dias após emergência (Durigan et al., 2005). Assim, o controle químico de plantas daninhas é uma prática bastante difundida em todo o país (FreITAS et al., 2004), porém, devido às similaridades entre as plantas daninhas e as cultivadas, a aplicação de herbicidas pode oferecer riscos de intoxicação à cultura (Negrisoli et al., 2004).

As variedades de cana-de-açúcar têm respostas diferenciadas aos herbicidas, e por consequência, frequentes problemas de fitointoxicação, por vezes reduzindo a produtividade do canavial (Procópio et al., 2004a). O desenvolvimento diferencial de genótipos de cana-deaçúcar diante de herbicidas (Velini et al., 2000; Procópio et al., 2004a), associado ao estádio de desenvolvimento desta cultura, são fatores importantes na tolerância de cultivares a tais defensivos (FERreira et al., 2005).

Os sintomas de fitotoxicidade provocados por herbicidas podem ser os danos estruturais (CARVALHO et al., 2009). A redução do comprimento de radículas, clorose acentuada ao longo do limbo foliar, necroses, albinismos, enrolamento e ressecamento de folhas a partir do ápice e da margem, menor espessura de colmos, morte de perfilhos (falhas de plantio), paralisação de crescimento e redução de altura (LóPEZOvejero et al., 2003; Barela e Christoffoleti, 2006).

O melhoramento genético convencional, aliado às técnicas bioquímicas e de biologia molecular, podem efetivamente desenvolver variedades tolerantes a herbicidas, e assim contribuir significativamente para diminuição dos custos envolvidos na produção da cultura, bem como das perdas inerentes à fitointoxicação promovida pela utilização de herbicidas. Entretanto há a necessidade de trabalhos iniciais que caracterizem a tolerância das variedades disponíveis a estes produtos. Este trabalho foi desenvolvido com o objetivo de realizar triagem primária para a caracterização da tolerância de variedades SP e CTC de cana-de-açúcar a dez herbicidas comumente recomendados para manejo de plantas daninhas nesta cultura.

Dois experimentos foram desenvolvidos em Piracicaba (SP) a $22^{\circ} 41^{\prime} \mathrm{S}, 47^{\circ} 41^{\prime} \mathrm{W}$ e $560 \mathrm{~m}$ de altitude, entre novembro e dezembro de 2006. Foram utilizadas plântulas de cana-de-açúcar (Saccharum spp.) com 30 dias após plantio (DAP), micropropagadas na biofábrica do CTC. As plantas foram cultivadas em vasos de $300 \mathrm{~mL}$, uma plântula por vaso, preenchidos com substrato estéril de areia e vermiculita $(2: 1, \mathrm{v}: \mathrm{v})$. $\mathrm{O}$ material foi transferido para casa-de-vegetação e aclimatado pelo período de 10 dias, sob condições controladas (temperatura de $25-32{ }^{\circ} \mathrm{C}$, irradiância de $300 \mu \mathrm{mol} \mathrm{m} \mathrm{m}^{-2} \mathrm{~s}^{-1}$ e fotoperíodo de $16 \mathrm{~h}$ ).

O delineamento experimental utilizado foi o de blocos ao acaso, com três repetições, e cada unidade experimental constou de cinco vasos com uma planta de cana-de-açúcar em cada vaso, totalizando 15 plantas por tratamento. Adotou-se esquema fatorial entre as variedades de cana-deaçúcar e onze tratamentos herbicidas. No primeiro experimento utilizaram-se sete variedades SP (fatorial 7 x 11): SP80-1842, SP80-3280, SP83-2847, SP87-344, SP87-396, SP89-1115 e SP90-3414. No segundo experimento, foram avaliadas seis variedades CTC (fatorial 6 x 11): CTC1, CTC2, СТC3, СTC4, СTC5 e CTC6.

Após a aclimatação das plântulas, procedeuse à aplicação dos tratamentos herbicidas em pós-emergência inicial, aos 40 dias após plantio (DAP), utilizando-se produtos e doses recomendados à cultura da cana-de-açúcar. Os tratamentos herbicidas, aplicados em pós-emergência inicial, foram: ametryn (2500 $\mathrm{g} \mathrm{ha}^{-1}$ de i.a.), ametryn + trifloxysulfuron-sodium $\left(1463+37 \mathrm{~g} \mathrm{ha}^{-1}\right.$ de i.a. $)$, clomazone (1100 $\mathrm{g} \mathrm{ha}^{-1}$ de i.a.), diuron + hexazinone $\left(1170+330 \mathrm{~g} \mathrm{ha}^{-1}\right.$ de i.a. $)$, isoxaflutole $\left(225 \mathrm{~g} \mathrm{ha}^{-1} \mathrm{de}\right.$ i.a.), imazapic (147 $\mathrm{g} \mathrm{ha}^{-1}$ de i.a.), 2,4-D (1005 $\mathrm{g} \mathrm{ha}^{-1}$ de i.a.), tebuthiuron (1200 $\mathrm{g} \mathrm{ha}^{-1}$ de i.a.), sulfentrazone (800 $\mathrm{g} \mathrm{ha}^{-1}$ de i.a.), MSMA (1920 $\mathrm{g} \mathrm{ha}^{-1}$ de i.a.) e testemunha sem aplicação. Para a aplicação dos herbicidas, utilizou-se equipamento pulverizador costal de precisão, pressurizado por $\mathrm{CO}_{2}$, operado a 40 psi, acoplado a uma única ponta de pulverização com jato do tipo plano, marca TeeJet $110.02 \mathrm{VS}$, promovendo largura efetiva de $0,5 \mathrm{~m}$ e volume de aplicação proporcional a $200 \mathrm{~L} \mathrm{ha}^{-1}$.

Aos 21 dias após os tratamentos (DAT), as folhas foram utilizadas para análise indireta do conteúdo total de clorofila por meio do aparelho Minolta SPAD 502 Meter (porção intermediária da folha +1). As partes aéreas das plantas foram amostradas no mesmo período para a realização das análises de altura dos colmos e massa fresca total da parte aérea. Também, aos 21 DAT, foram amostrados os microtoletes para análise de perfilhamento.

Para permitir a comparação das variedades naturalmente diferentes, as variáveis foram expressas em porcentagem, por meio da comparação dos valores 
obtidos nos tratamentos herbicidas com a testemunha, considerada 100\%. Em cada experimento, os dados de todas as variáveis foram submetidos à aplicação do teste F na análise da variância. Nos casos de significância de efeitos, as diferenças entre as médias das variáveis avaliadas foram agrupadas pelo teste de Scott-Knott, com $5 \%$ de significância (ScOTT e KNOTT, 1974). Após aplicação dos herbicidas, resultados próximos, iguais ou superiores a $100 \%$ (testemunha) evidenciaram maior tolerância da variedade. Desta forma, para as diferentes combinações variedadeherbicida, classificaram-se as variedades de cana-de-açúcar em tolerantes, intermediárias e sensíveis, considerando-se a freqüência com que cada variedade aparece no grupo superior ou inferior pelo teste de Scott-Knott. Discussão particular foi desenvolvida com relação ao perfilhamento.

Com a aplicação do teste $F$ na análise da variância, identificou-se a significância da interação fatorial (herbicidas $x$ variedades) para todas as variáveis avaliadas, em ambos os experimentos. Assim, os efeitos isolados dos fatores foram desconsiderados e analisaram-se detalhadamente as interações (Tabelas 1 a 4). Considerando-se que o objetivo deste trabalho foi realizar triagem primária de tolerância diferencial das variedades de cana-deaçúcar, optou-se por não realizar comparação dos herbicidas, visto que a recomendação prática de aplicação em campo não é a mesma para todos eles.

A seletividade de um herbicida está relacionada com a capacidade do agroquímico em eliminar as plantas daninhas que infestam as culturas agrícolas, sem reduzir a produtividade e a qualidade do produto final obtido (NEGRISOLI et al., 2004; Carvalho et al., 2009). Neste sentido, a determinação da massa fresca da parte aérea, a altura dos colmos e o conteúdo total de clorofila de plantas de cana-de-açúcar, podem ser variáveis práticas para o estudo da tolerância a herbicidas.

No primeiro experimento, a variedade SP87-344 foi identificada como a mais sensível à aplicação de herbicidas, resultando em menores valores de massa fresca e altura de plantas (Tabela 1). Além disso, observou-se também que esta variedade foi particularmente mais sensível ao herbicida clomazone, com valor de massa reduzido quando comparado com as demais. Constatou-se tolerância intermediária das variedades SP87-396, SP90-3414, SP80-1842 e SP89-1115 à aplicação de herbicidas, resultando em massa ou altura reduzidas para determinados herbicidas, destacando-se a variedade SP80-1842. FERREIRA et al. (2005) observaram comportamento similar em experimentos realizados com trifloxysulfuronsodium + ametryn. Ainda, SP87-396 foi particularmente sensível ao herbicida isoxaflutole (Tabela 1).

Os herbicidas isoxaflutole, tebuthiuron, ametryn, sulfentrazone e clomazone, aplicados em doses representativas às utilizadas comercialmente, foram seletivos à cana-de-açúcar RB85-5113, não afetando seu crescimento e sua produtividade até 40 dias após aplicação (NEGRIsoli et al., 2004). No caso da variedade RB83-5089, aos 45 dias após a aplicação em pós-emergência tardia, os herbicidas isoxaflutole e diuron + hexazinone afetaram a altura das plantas e o rendimento agrícola (AzANIA et al., 2006). No presente trabalho, a aplicação de diuron + hexazinone sobre SP80-3280 resultou na mais expressiva inibição de crescimento dentre as variedades, com os menores índices de altura e biomassa (Tabela 1). Em nenhuma das variedades SP se observou alta sensibilidade ao herbicida 2,4-D.

Destacam-se as variedades SP80-3280 e SP832847 como as mais tolerantes aos herbicidas, cujos valores de biomassa e altura estiveram próximos aos da testemunha $(100 \%)$ para a grande maioria dos tratamentos herbicidas utilizados (Tabela 1). Ferreira et al. (2005) observaram comportamento similar para a variedade SP80-1842. Estes autores avaliaram a sensibilidade de 11 variedades e quatro clones de cana-de-açúcar ao herbicida ametryn + trifloxisulfuron-sodium, aos 45 dias após aplicação dos tratamentos. A variedade RB85-5113 foi a mais sensível a este herbicida, com biomassa $67 \%$ e altura $30 \%$ inferior à testemunha sem aplicação, enquanto para as mesmas variáveis, RB86-7515 foi a variedade com maior tolerância às aplicações de 1,0 e 2,0 kg ha${ }^{1}$ de p.c.

No segundo experimento, identificou-se CTC2 como a variedade mais tolerante à aplicação de herbicidas em pós-emergência, visto que obteve os maiores acúmulos de massa fresca e altura (Tabela 2), quando submetida a qualquer herbicida. Considerando-se essa testemunha como $100 \%$, houve redução expressiva de massa fresca somente quando submetida à aplicação de imazapic, sintoma este também observado em todas as variedades, nos dois experimentos (Tabelas 1 e 2). Neste momento, vale destacar que as recomendações tradicionais de aplicação de imazapic não prevêem uso em pós-emergência de cana-planta (Rodrigues e Almeida, 2005); este procedimento foi realizado apenas para estimativa experimental da atividade metabólica das variedades. 


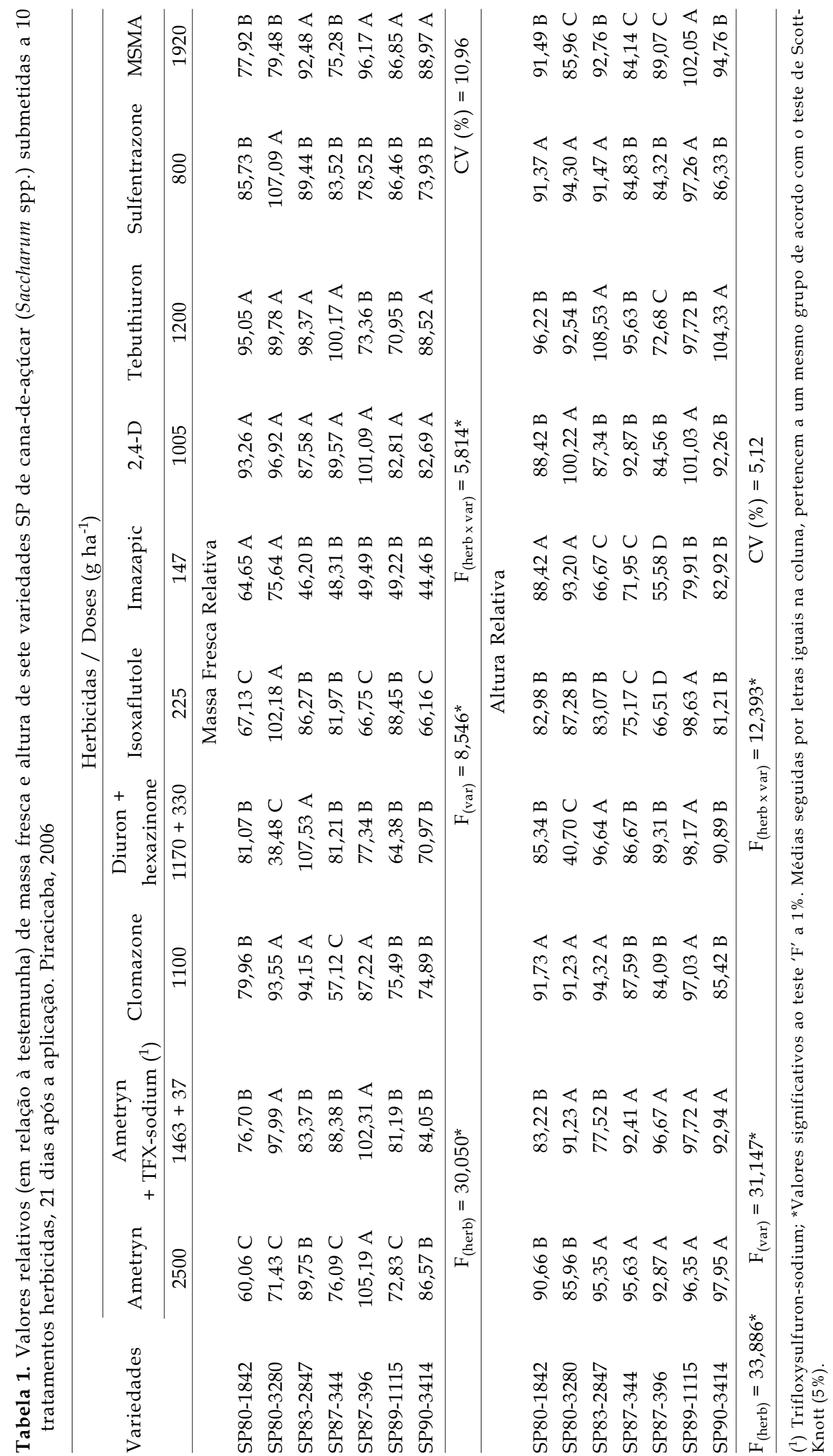




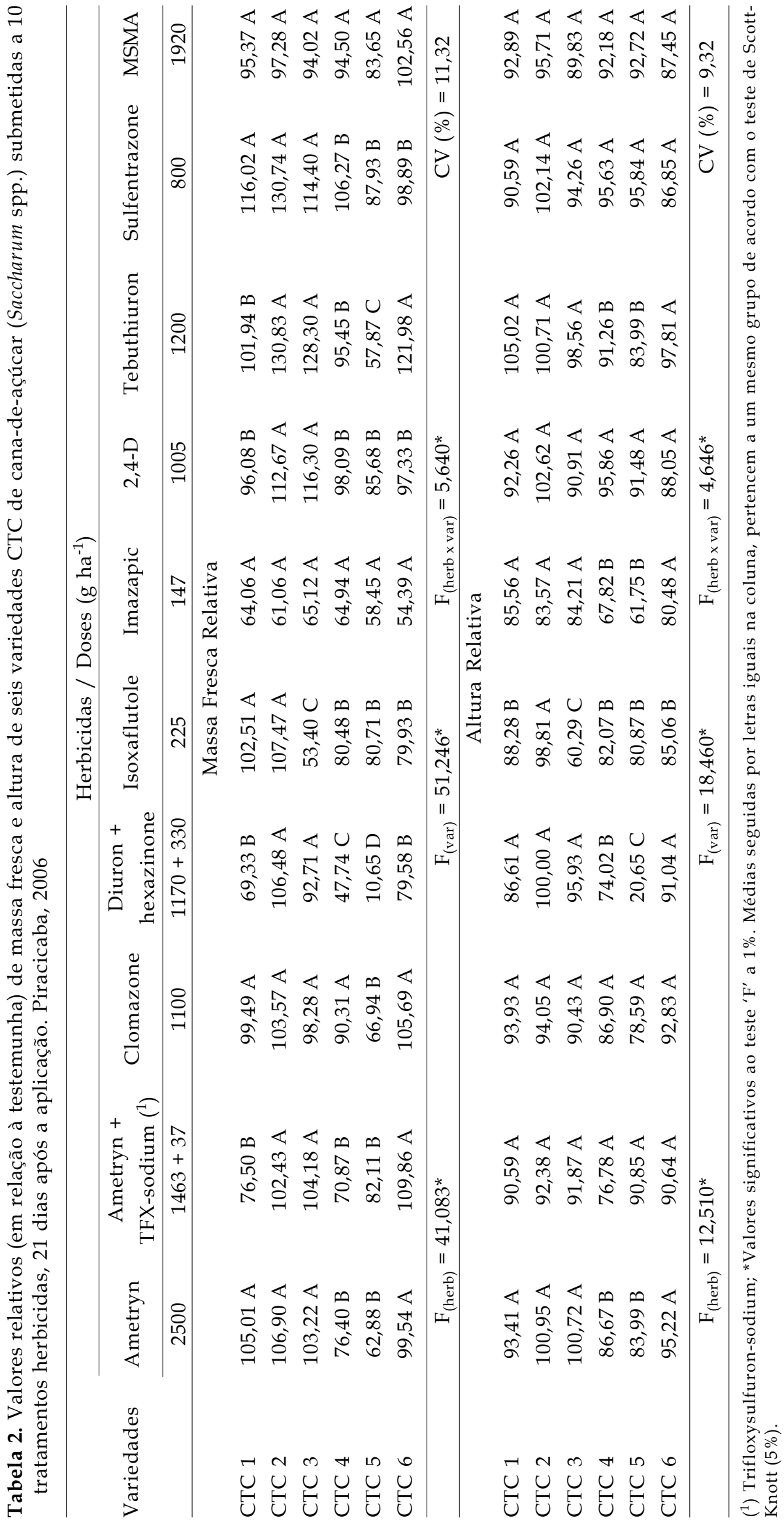




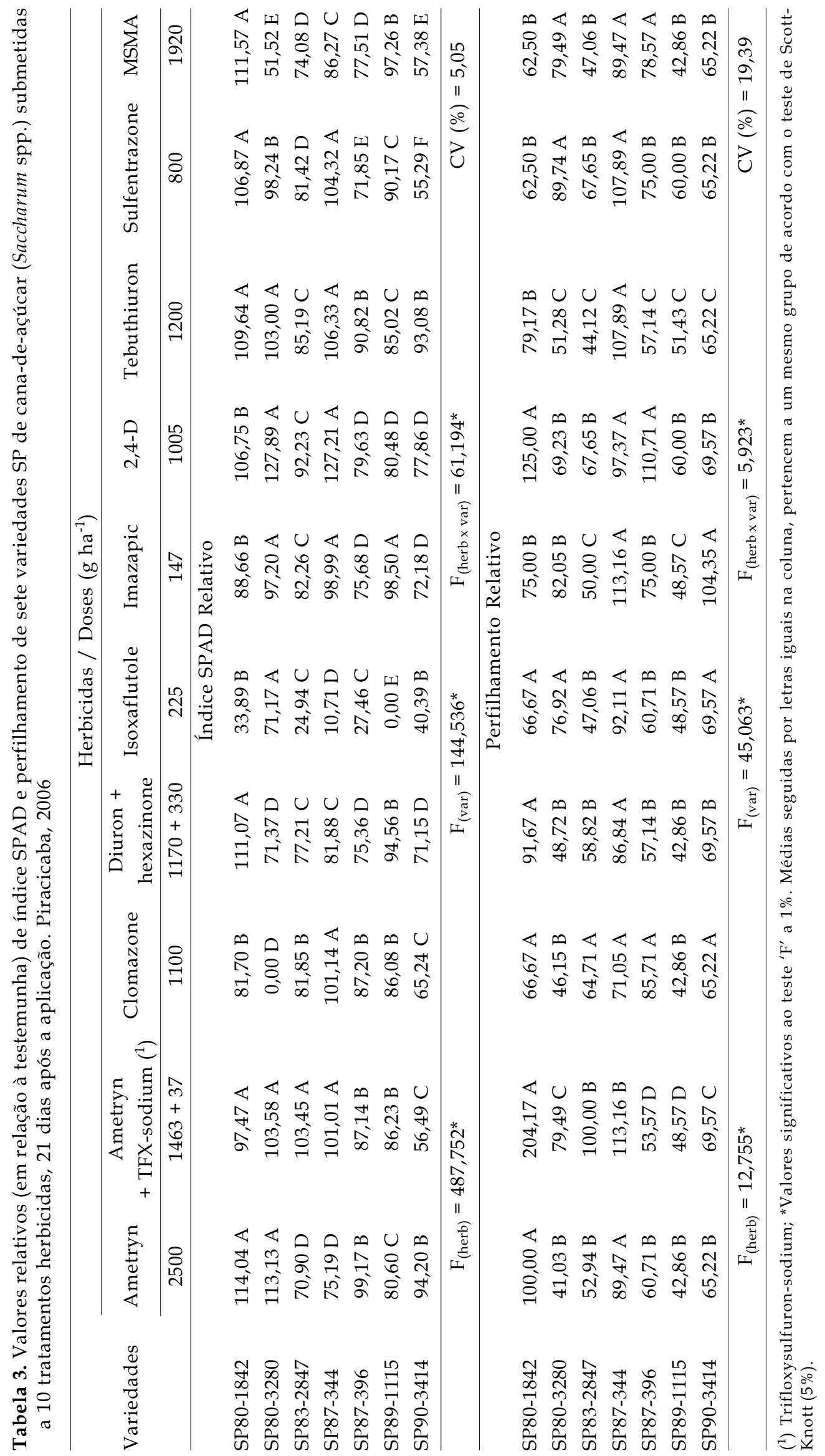




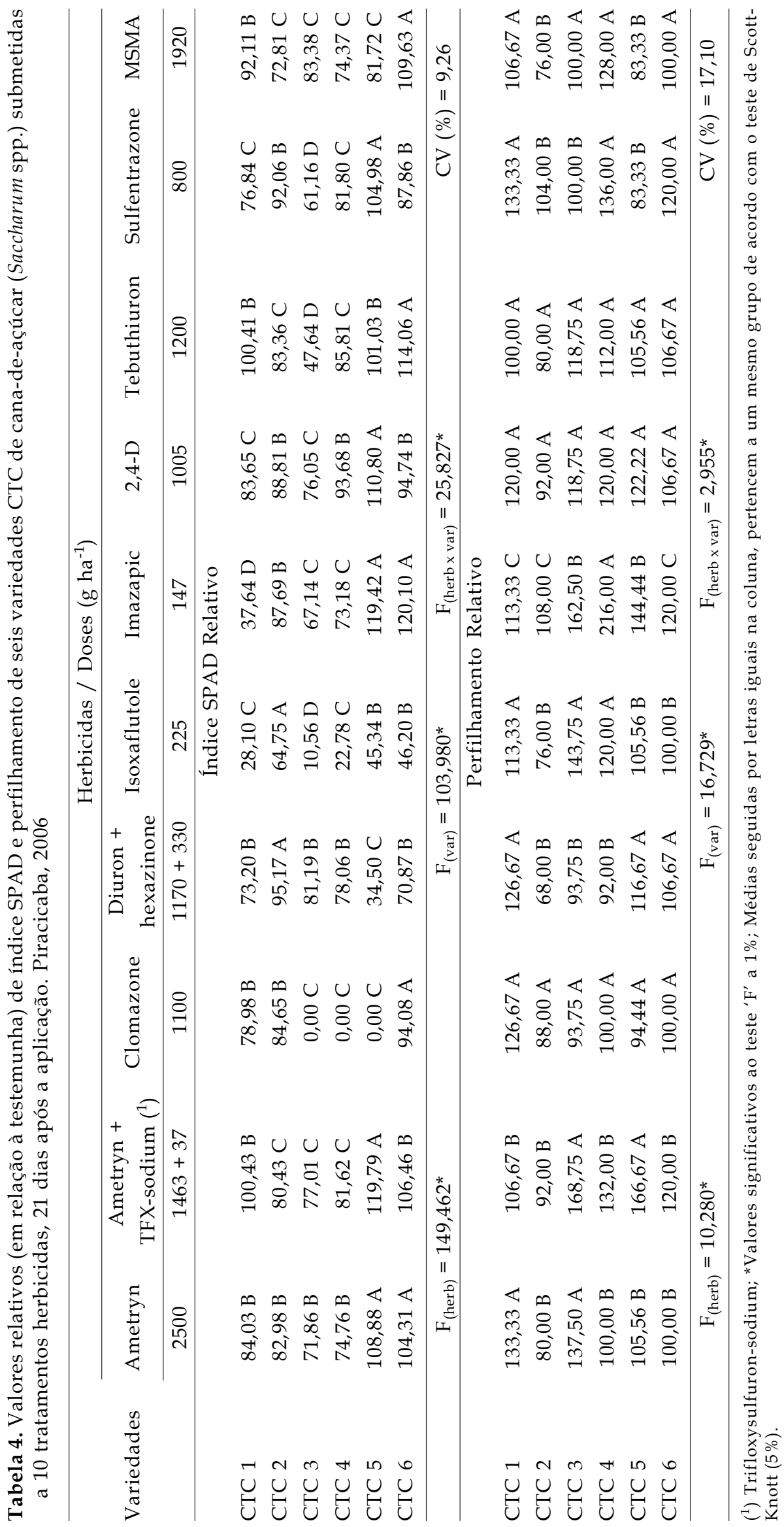


Em geral, as variedades CTC4 e CTC5 foram as mais sensíveis à aplicação de herbicidas, resultando em menores valores de massa fresca e altura de plantas (Tabela 2). Neste aspecto, constatou-se que a variedade CTC5 foi extremamente sensível ao herbicida diuron + hexazinone, com valores de massa e altura bastante reduzidos quando comparados com as demais. As variedades CTC1, CTC3 e CTC6 tiveram tolerância intermediária à aplicação de herbicidas, resultando em massa ou altura reduzidas para determinados herbicidas; a variedade CTC3, por exemplo, foi identificada como altamente sensível ao herbicida isoxaflutole (Tabela 2).

Com relação à clorofila, destacaram-se a alta sensibilidade das variedades SP90-3414, SP87-396 e SP83-2847 aos herbicidas aplicados, representada pela ausência de valores iguais ou superiores a $100 \%$, com destaque à diminuição acentuada do teor de clorofila induzida por ametryn + trifloxysulfuronsodium, sulfentrazone e MSMA na variedade SP90-3414 (Tabela 3). A maioria das combinações herbicida-variedade resultou em fitointoxicação, representada pela substancial ocorrência de índices SPAD menores que $100 \%$ (testemunha). As variedades SP80-1842 e SP80-3280, por sua vez, foram as mais tolerantes aos danos foliares causados pela aplicação de herbicidas em pós-emergência, caracterizados pela ocorrência de valores próximos, iguais e superiores a $100 \%$ (Tabela 3).

Ainda em relação a SP80-3280, vale destacar que o teor de clorofila foi significativamente baixo ao se aplicar clomazone, de modo que não foi atingido o nível mínimo de detecção do SPAD (Tabela 3), sugerindo que esta variedade possui alta sensibilidade ao mecanismo de ação deste herbicida, que está relacionado com a inibição da síntese de carotenos (CARVALHO, 2004). De forma contraditória, embora em todas as variedades tenha ocorrido diminuição na clorofila, SP80-3280 foi a que revelou maior tolerância ao isoxaflutole. Foi possível ainda observar, nesta variedade, forte diminuição no teor de clorofila decorrente da utilização de diuron + hexazinone e MSMA (Tabela 3).

Com relação ao perfilhamento relativo (Tabela 3), destaca-se SP87-344 como a variedade com maiores níveis e homogeneidade de perfilhamento. Em geral, para as demais variedades, observou-se menor quantidade de perfilhos nas plantas tratadas com herbicidas, o que pode estar relacionado com a ocorrência de elevados danos, devido à aplicação de herbicidas em pós-emergência nas plantas apenas em início de desenvolvimento. A homogeneidade de perfilhos de SP87-344, por outro lado, pode estar relacionada com a ocorrência de danos ou morte nos perfilhos primários e, consequentemente, estímulo à emissão de grande número de novos perfilhos. Esse fato explicaria o menor perfilhamento de SP80-3280, que foi a variedade com os maiores valores de biomassa (Tabela 1).

Assim, de acordo com a tolerância das variedades SP a herbicidas, pode-se sugerir que potencialmente, a variedade de cana-de-açúcar SP803280 é a mais indicada para programas de melhoramento. Além disso, devido à maior tolerância apresentada, outros estudos podem ser desenvolvidos com esta variedade, visando a outras aplicações tecnológicas, como a fitorremediação de herbicidas com longo efeito residual no solo. Efetivamente, esta temática representa um sério problema ecotoxicológico, pois é grande a possibilidade de lixiviação dessas moléculas ou de seus metabólitos para camadas mais profundas do solo, podendo atingir o lençol freático (Pires et al., 2003; Procópio et al., 2004b).

Considerando os materiais CTC, a maioria das combinações herbicida-variedade também resultou em fitotoxicidade, representada pela substancial ocorrência de índices SPAD menores que 100\% (testemunha). Dentre as variedades estudadas, a CTC6 foi a mais tolerante aos danos foliares causados pela aplicação de herbicidas em pós-emergência, caracterizados pela ocorrência de valores próximos, iguais e superiores a $100 \%$. As variedades CTC1, CTC3 e CTC4, por sua vez, foram as mais sensíveis aos herbicidas, com ausência de valores iguais ou superiores a $100 \%$ (Tabela 4).

Observou-se alta suscetibilidade da variedade CTC3 a danos foliares causados pelos herbicidas (Tabela 4), representada pela ausência de valores iguais ou superiores a $100 \%$, com destaque aos sintomas causados pelos herbicidas clomazone e isoxaflutole. Estes sintomas estão em concordância com o mecanismo de ação dos produtos, ou seja, a inibição da síntese de carotenóides e, consequentemente, destruição celular e de clorofilas, o que provoca o albinismo das plantas sensíveis (Kruse, 2001; Carvalho, 2004). Em relação a estes herbicidas, as variedades mais tolerantes foram CTC6 e CTC2 respectivamente.

Azania et al. (2005) observaram que, em pósemergência inicial (27 dias pós- colheita) e em pós-emergência tardia (55 dias pós-colheita), o herbicida isoxaflutole prejudicou a produtividade agrícola e diminuiu significativamente os teores de clorofila na variedade de cana-de-açúcar RB83-5089, enquanto diuron + hexazinone, em pós-emergência tardia, diminuiu a concentração de clorofila, sem alteração na produtividade. 
Com relação ao perfilhamento percentual relativo (Tabela 4), destaca-se CTC2 como a variedade com menor estímulo à emissão de perfilhos. Em geral, nas demais variedades, observou-se maior quantidade de perfilhos nas plantas tratadas com herbicidas, o que pode estar relacionado com a ocorrência de danos ou morte nos perfilhos primários e, conseqüentemente, estímulo à emissão de grande número de novos perfilhos, o que explicaria o menor perfilhamento de CTC2, porém com as maiores massas frescas (Tabela 2).

A caracterização primária da tolerância de variedades de cana-de-açúcar a herbicidas é de suma importância para o desenvolvimento de programas de melhoramento genético focados em variedades com menor fitointoxicação. Têm-se, também, oportunidade de alocação destas variedades em áreas com maior contaminação por defensivos, a fim de contribuir para fitorremediação do ambiente agrícola. Ainda, pode-se optar por sistemas de escolha de herbicidas que considerem aspectos como tolerância varietal, disponibilidade de herbicidas, custos e rendimento. Para tanto, maiores estudos precisam ser desenvolvidos, correlacionando a tolerância das variedades de canade-açúcar com níveis endógenos de atividade metabólica, principalmente as mediadoras de metabolismo de degradação de herbicidas, tais como as glutationa-S-transferases e complexos citocromos P-450s.

Nas variedades de cana-de-açúcar observouse tolerância diferencial aos herbicidas comumente utilizados na cultura; SP80-3280 e CTC2 foram as mais tolerantes à aplicação de herbicidas, podendo ser esta característica explorada em programas de melhoramento genético.

\section{AGRADECIMENTOS}

À FAPESP pelo apoio financeiro ao trabalho (06/52330-0; 06/60196-2); pela bolsa de estudos de Pós-Doutorado (04/10614-7) a Renato R. Ferreira; pela bolsa de estudos de Iniciação Científica (06/604050) a Fabrício T. R. Oliveira. Ao Dr. Alexandre M. Sebbenn, pelas orientações estatísticas; ao Sr. Wlamir A. Godoy, pelo apoio técnico e ao Centro de Tecnologia Canavieira, pela parceria e fornecimento do material vegetal.

\section{REFERÊNCIAS}

AZANIA, C.A.M.; ROLIM, J.C.; CASAGRANDE, A.A.; LAVORENTI, N.A.; AZANIA, A.A.P.M. Seletividade de herbicidas. III - Aplicação de herbicidas em pós-emergência inicial e tardia da cana-de-açúcar na época da estiagem. Planta Daninha, v.24, p.489-495, 2006.
AZANIA, C.A.M.; ROLIM, J.C.; CASAGRANDE, A.A.; LAVORENTI, N.A.; AZANIA, A.A.P.M. Seletividade de herbicidas. II - Aplicação de herbicidas em pós-emergência inicial e tardia da cana-de-açúcar na época das chuvas. Planta Daninha, v.23, p.669-675, 2005.

BARELA, J.F.; CHRISTOFFOLETI, P.J. Seletividade de herbicidas aplicados em pré-emergência da cultura da canade-açúcar (RB 867515) tratada com nematicidas. Planta Daninha, v.24, p.371-378, 2006.

CARVALHO, J.C. Mecanismo de ação de herbicidas e sua relação com a resistência a herbicidas. In: CHRISTOFFOLETI, P.J. (Coord.). Aspectos da resistência de plantas daninhas a herbicidas. 2.ed. Londrina: HRACBR, 2004. p.23-48.

CARVALHO, S.J.P.; NICOLAI, M.; FERREIRA, R.R.; FIGUEIRA, A.V.O.; CHRISTOFFOLETI, P.J. Herbicide selectivity by differential metabolism: considerations for reducing crop damages. Scientia Agricola, v.66, p.136$142,2009$.

DURIGAN, J.C.; TIMOSSI, P.C.; CORREIA, N.M. Densidades e manejo químico da tiririca na produtividade de cana-de-açúcar. Planta Daninha, v.23, p.463-469, 2005.

FERREIRA, E.A.; SANTOS, J.B.; SILVA, A.A.; VENTRELLA, M.C.; BARBOSA, M.H.P.; PROCÓPIO, S.O.; REBELLO, V.P.A. Sensibilidade de cultivares de cana-de-açúcar à mistura de trifloxysulfuron-sodium + ametryn. Planta Daninha, v.23, p.93-99, 2005.

FREITAS, S.P.; OLIVEIRA, A.R.; FREITAS, S.J.; SOARES, L.M.S. Controle químico de Rottboelia exaltata em cana-de-açúcar. Planta Daninha, v.22, p.461-466, 2004.

KRUSE, N.D. Inibidores da síntese de carotenóides. In: VIDAL, R.A.; MEROTTO JR., A. (Ed.) Herbicidologia. Porto Alegre, 2001. p.113-122.

LÓPEZ-OVEJERO, R.F.; FANCELLI, A.L.; DOURADO NETO, D. Manejo de plantas daninhas na cultura do milho. In: FANCELLI, A. L.; DOURADO NETO, D. Milho: estratégias de manejo para alta produtividade. Piracicaba: ESALQ, 2003. p.47-79.

NEGRISOLI, E.; VELINI, E.D.; TOFOLI, G.R.; CAVENAGHI, A.L.; MARTINS, D.; MORELLI, J.L.; COSTA, A.G.F. Seletividade de herbicidas aplicados em pré-emergência na cultura de canade-açúcar tratada com nematicidas. Planta Daninha, v.22, p.567$575,2004$.

PIRES, F.R.; SOUZA, C.M.; SILVA, A.A.; QUEIROZ, M.E.L.R.; PROCÓPIO, S.O.; SANTOS, J.B.; SANTOS, E.A.; CECON, P.R. Seleção de plantas com potencial para fitorremediação de tebuthiuron. Planta Daninha, v.21, p.451-458, 2003.

PROCÓPIO, S. O.; SILVA, A.A.; VARGAS, L. Manejo e controle de plantas daninhas em cana-de-açúcar. In: VARGAS, L.; ROMAN, E. S. (Eds.). Manual de manejo e controle de plantas daninhas. Bento Gonçalves: Embrapa Uva e Vinho, 2004a. p.397-452. 
PROCÓPIO, S.O.; SANTOS, J.B.; SILVA, A.A.; PIRES, F.R.; RIBEIRO JÚNIOR, J.I.;SANTOS, E.A.; FERREIRA, L.R. Seleção de plantas com potencial para fitorremediação de solos contaminados com o herbicida trifloxysulfuron sodium. Planta Daninha, v.22, p.315-322, 2004b.

RODRIGUES, B.N.; ALMEIDA, F.S. Guia de herbicidas. 5.ed. Londrina, 2005. 592p.

SCOTT, A.J.; KNOTT, M. A cluster analysis method for grouping means in the analysis of variance. Biometrics, v.30, p.507-512, 1974 .

VELINI, E.D.; MARTINS, D.; MANOEL, L.A.;MATSUOKA, S.; TRAVAIN, J.C.; CARVALHO, J.C. Avaliação da seletividade da mistura de oxyfluorfen e ametryne, aplicada em pré e pósemergência, a dez variedades de cana-de-açúcar (cana planta).

Planta Daninha, v.18, p.123-134, 2000. 